\title{
O Haiti e suas possibilidades: visões sobre uma realidade (in)acabada
}

\author{
Romulo Thiago Oliveira de Sousa ${ }^{1}$
}

SANTIAGO, Adriana (Org.). Haiti por si: A reconquista da independência roubada. Adriana Santiago [organizadora]. Fortaleza: Expressão Gráfica e Editora, 2013. 191 p.

\section{Resenha recebida em: 06/02/2014}

Resenha aprovada em: 10/05/2014

O livro Haiti por si: A reconquista da independência roubada trata-se uma organização de artigos e reportagens de diversos autores, tanto do Haiti, quanto de outras nacionalidades e possui textos e fotos que chamam a atenção dos leitores e do povo haitiano para que percebam as reais possibilidades de autogestão do Haiti. A partir do convite da Agência de Informação Frei Tito para América Latina (Adital), a jornalista Adriana Santiago, mestre em Comunicação e Cultura Contemporâneas (UFBA) e professora de jornalismo na Universidade de Fortaleza (Unifor) desde 2006, além de ter sido editora-chefe da Adital de 2003 a 2006 e hoje colaboradora de projetos especiais, foi chamada para organizar este livro que está dividido em seis capítulos com eixos temáticos diferentes que mostram trajetos propostos pelos próprios haitianos para a reconstrução do país: história, reconstrução, economia solidária, soberania alimentar, cultura e democracia participativa.

O livro está dividido em capítulos e cada parte, com uma linha de investigação própria, subdividido em tópicos e cada capítulo apresenta artigos jornalísticos intercalados de forma a complementar o assunto tratado. "Colaboraram com os capítulos deste livro, os jornalistas haitianos Woody Edson Louidor, Nélio Joseph, James Alexis (fotos) e Phares Jerôme, este último com três capítulos. Além com dos articulistas Irdèle Lubin, Rochelle Doucet, Alain Gilles, Pierre Clitandre e Marie Frantz Joachim. Do Brasil, temos Adriana Santiago, Ermano Allegri, o jornalista Benedito Teixeira e Frei Beto. Além da colaboração da jornalista chilena, Francisca Stuardo, que fotografou e escreveu para o livro" (Santiago, 2013, p.11).

O livro é resultado de várias pesquisas e entrevistas que têm como finalidade mostrar as diversas possibilidades que o Haiti possui de autogestão, imprimindo um foco nas possibilidades inerentes que o país possui para sair de uma crise que se diz crônica, amplamente divulgada. É feita uma reflexão sobre a reconstrução na retomada do controle da nação. A situação social caótica do Haiti também é reflexo da ajuda humanitária que transformou o país em uma das principais fontes de recursos de

\footnotetext{
${ }^{1}$ Graduando em História pela Universidade Federal do Amazonas. Email: thiarom@gmail.com

Revista Eletrônica da ANPHLAC, ISSN 1679-1061, n. 16, p. 249-255, Jan./Jul. 2014. http://revista.anphlac.org.br
} 
milhares de ONGs que atuam há décadas no país, mas não produzem resultados que consigam, de fato, melhorar de forma sustentável a vida do povo. E o terremoto veio aprofundar essa situação de dificuldades, pois grande parte do apoio financeiro internacional anunciado não foi efetivada. No entanto, mesmo diante desse quadro desanimador, a organização do livro mostra que existe uma essência lutadora no povo haitiano: um conjunto de movimentos de mulheres, campesinos, universitários, etc., que com suas ações e o devido tratamento pelo Estado e pela importância da ajuda humanitária internacional, podem fortalecer as iniciativas de democracia participativa.

"Haiti por si" está dividido em seis capítulos, o primeiro capítulo denominado de Uma história paradoxal, escrito por Woody Edson Louidor, faz uma breve apresentação geográfica e sócio-demográfica do Haiti antes de esboçar o panorama histórico desse país caribenho. O autor nos faz compreender o Haiti que nos foi apresentado depois do terremoto 12 de janeiro de 2010 nos obrigando a retroceder muito antes do desastre que devastou o país. Ele diz ser necessário compreender a história do país caribenho para podermos depreender a vulnerabilidade do mesmo frente ao terremoto, visto que esta fragilidade é resultado de um longo processo que começa desde a colonização espanhola e francesa até hoje, passando pela ocupação estadunidense no país e a irresponsabilidade das autoridades haitianas, que não têm elaborado políticas públicas destinadas a reduzir esta vulnerabilidade.

O autor nos diz que a história do Haiti tem sido também uma história de rebelião contra a "elite local" do País que tem mantido desde sempre a maioria da população em uma situação de exclusão social, pois além das lutas contra as invasões externas há uma história de exclusão social interna e da luta pela emancipação. $O$ autor traça um panorama histórico desde a chegada dos primeiros europeus em solo americano e da resistência dos nativos frente aos povos dominadores, e a partir deste encontro de dois mundos diferentes que começa uma história de invasão, colonização, dominação, racismo, e ao mesmo tempo de resistência, rebelião e luta pela liberdade.

Um dos momentos culminantes que define a sociedade haitiana, para o autor é o momento de independência do País. A França conseguiu em 1967, que a Espanha lhe cedesse a parte ocidental da ilha, chamada pelos franceses de Saint-Domingue (hoje, Republica do Haiti) através do Tratado de Ryswick, e depois do extermínio, praticado de diversas formas, dos grupos étnicos existentes no "novo" mundo, era necessário buscar outra mão de obra escrava para sustentar a ordem escravagista. Depois de implantado o tratado negreiro, milhares de escravos negros adentraram a ilha de SaintDomingue sofrendo variados tipos de maus tratos, o que consequentemente levou à rebelião dos negros escravos que se utilizaram de diversas formas de resistência e estratégias de organização para luta contra a colonização francesa. Esse processo de independência do país e constituição de uma "República Negra" representou uma ameaça para os países escravocratas. No entanto, a liberdade custou caro para o Haiti que foi sujeitado a pagar uma indenização à França, que o empurrou a contrair uma dívida pública, o que consequentemente levou o país a adotar uma economia de 
exportação, ao invés de uma economia voltada para satisfação das necessidades básicas de seus cidadãos.

O autor depois de discorrer sobre as sucessivas invasões no território haitiano ajuda-nos a enxergar uma contra-história do Haiti que tem sido, por sua vez, de invasão e rebelião, de dominação externa e resistência, de vulnerabilidade social e resiliência, de exclusão social e luta pela emancipação. Que a invasão nunca teve a última palavra, para evitar que a palavra da rebelião seja esquecida, o autor nos fala que é necessário romper com a violência "sistêmica" fabricada por um discurso orientado a justificar a dependência militar, financeira e político-econômica do Haiti. Definitivamente este é um país que segue sendo desconhecido no mundo. $\mathrm{O}$ elemento primordial para compreender a história do Haiti é a rebelião e não só a invasão, a conquista, ocupação, e escravidão, já que a rebelião permite contar de outra maneira a história a dos de baixo, pois o autor enfatiza o "historicídio" do qual o Haiti tem sido vítima. Deve-se resgatar a contra-história do Haiti, que é a história de rebelião frente às diferentes formas históricas de invasão e exclusão, e como isto permitiu reconstruir outro Haiti, outro Haiti inclusivo, democrático, soberano, livre e prospero exatamente o país com o qual havia sonhado o povo haitiano na Constituição de 1987.

O segundo capítulo denominado de Depois da catástrofe, como estamos?, escrito por Phares Jerôme, busca relatar a situação do Haiti depois do terremoto que ocasionou um desastre que deixando danos impressionantes que continuam afetando de modo intenso e direto os haitianos. $\mathrm{O}$ autor utiliza dos dados proporcionados por diferentes entidades haitianas e internacionais, e conclui que Haiti apresenta um quadro geral desolador, mas apesar dessa extrema vulnerabilidade social historicamente produzida, o povo haitiano tem mostrado uma grande capacidade de resistência aos constantes choques que os afetam diretamente. Pois este povo já por si era vítima de uma forte exclusão social geradora de pobreza e de instabilidade política. O autor é enfático ao dizer que a catástrofe que o terremoto gerou foi principalmente social devido à exclusão e a produção histórica da vulnerabilidade social no país, ainda que grande parte das primeiras interpretações acerca de tal catástrofe social fosse de ordem sobrenatural, acusou-se a tradição africana do vodu de ser a principal causa do desastre.

Depois do terremoto de 2010, foi necessária uma ajuda maciça e rápida da comunidade internacional, incluindo os países da America Latina, para evitar uma catástrofe humanitária em Porto Príncipe. Mais de dois anos após o terremoto, o país ainda não conseguiu cicatrizar as feridas do desastre já que o processo de reconstrução anunciado com grande alarde após o terremoto não alcançou o seu objetivo. Em seu artigo, o autor diz que alguns fatores sociais estimam que o País ainda encontra-se em situação de urgência humanitária além da vulnerabilidade elevada do Haiti às catástrofes naturais durante as estações de chuvas e furações que são também levadas em consideração. E paralelamente, a ação de ONGs internacionais e doadores, as organizações sociais haitianas tem a sua própria avaliação das ações desenvolvidas nos acampamentos. A maioria dessas organizações se reúne numa plataforma com a 
intenção de ter suas vozes ouvidas no processo de reconstrução do país. A plataforma denominada, em crioulo haitiano, de "Je nan Je" visa a obtenção da garantia do direito a terra e a habitação decente no Haiti, focada na transparência, responsabilidade e boa governança. Outro movimento de organizações sociais, chamado Coletivo de Organizações Haitianas pelo Respeito do Direito à Habitação foi criado para defender o direito à moradia das vítimas do terremoto de 12 de janeiro de 2010. O Grupo de Apoio aos Refugiados e Repatriados (GARR), luta pelo processo de resgate da cidadania e da soberania do povo haitiano, promove e defende os direitos dos migrantes haitianos. Estas organizações visam ajudar a melhorar as condições de vida de pessoas atingidas pelo terremoto na área econômica, social e ambiental.

O autor nos diz que as ONGs são cada vez mais numerosas a ponto do Haiti ser conhecido como a República das ONGs, e estas organizações estão em quase todas as áreas relacionadas ao desenvolvimento e ajuda humanitária, incluindo serviços essenciais que deveriam ser gerenciados pelo governo haitiano e o fato é que essas ONGs são dotadas de melhores orçamentos do que a instituição responsável por controla-las. E elas são frequentemente acusadas de desvio e má aplicação da verba destinada à ajuda aos haitianos e de agir como um Estado dentro do Estado.

Já o terceiro capítulo com o título de Soberania Alimentar: um território agrícola em agonia escrito por Phares Jerôme, mostra-nos que todas as dificuldades que o Haiti possui no setor agrícola geram fome e desnutrição que por sua vez, atingem uma boa parte da população são consequências da falta de programações integradas em grande escala em relação à nutrição e a segurança alimentar. A catástrofe de janeiro de 2010 não poupou o setor agrícola e não há duvidas de que a tragédia agravou os problemas estruturais que a agricultura enfrenta e reduziu ainda mais a capacidade do governo de enfrentá-los. O autor destaca que, no passado, o Haiti era um país autossuficiente em matéria alimentar, mas hoje, fatores contrariam o avanço da economia no Haiti: a falta de investimento no setor, a crise política recorrente e o empréstimo mal feito de recursos financeiros.

Este capítulo nos apresenta as características e problemáticas do setor agrícola dos principais departamentos do Haiti e o trabalho de algumas organizações sociais que trabalham em conjunto com os campesinos, por exemplo, Artibonite, o segundo departamento do país em termos de população, é o primeiro produtor nacional de cereais, principalmente o arroz. Como no resto do país, os agricultores artibonenses confrontam-se com muitos problemas como a concorrência com produtos importados, a liberação do mercado dos produtos agrícolas, os riscos de inundação, perdas de colheitas nas zonas de produção e a diminuição dos espaços cultiváveis. Apesar de todos esses problemas, os agricultores de Artibonite tiveram força e criaram em 2001 a Rede das Associações Cooperativas para a Comercialização e Produção Agrícola do Baixo Artibonite (Racpaba), estruturaram em 2012 a Federação Nacional dos Produtores de Arroz do Haiti (Fenaprih) para defender seus direitos, e também eles dispõem de seu próprio organismo de desenvolvimento rural, o Desenvolvimento do 
Vale de Artibonite (ODVA). Há uma luta constante de organizações que reivindicam investimentos em infraestruturas agrícolas em todo o País, e também a aplicação de taxas aduaneiras sobre o arroz importado, o que implica em uma competição desleal dos produtos importados. É difícil dissociar a situação de segurança alimentar da situação do setor agrícola que é o principal provedor de bens alimentares da população, ou seja, com todas as dificuldades que o setor enfrenta, a população haitiana se encontra em situação de insegurança alimentar.

No capítulo quatro, que tem como título Uma Alternativa de Desenvolvimento Econômico e Social, desenvolvido por Phares Jerôme, são apresentados as alternativas de desenvolvimento socioeconômico concebidas pelos próprios haitianos. Alguns especialistas acreditam que o Haiti, a partir da economia social e solidaria, é capaz de mobilizar recursos locais para se reconstruir. Uma alternativa à ajuda internacional que nem sempre chega ao momento desejado. $\mathrm{O}$ autor exemplifica afirmando que este tipo de economia se opõe diretamente à atual economia de mercado - neoliberal - instalada no País, que busca apenas o lucro. Para muitos especialistas e profissionais em economia solidaria, há uma falta de reconhecimento desse setor pelo Estado haitiano. Os Bancos Comunitários, os grupos de ajuda mútua solidária e as cooperativas financeiras e não financeiras são as principais instituições de economia solidária identificadas no país atualmente.

E ao falar de experiências de economia solidárias bem sucedidas no Haiti, o autor não deixa de falar de Lèt Agogo, um programa de apoio ao desenvolvimento da produção do leite. Esse programa é realizado pela Veterimed, uma organização não governamental criada em 1991 por um grupo de veterinários haitianos a fim de contribuir para o desenvolvimento nacional por meio de atividades das áreas rurais. Os produtos da rede Lèt Agogo são distribuídos principalmente nas escolas, e no âmbito do Programa Nacional de Alimentação Escolar (PNCS), a parceria entre a Veterimed e PNCS constitui um modelo de valorização da produção local e de uma empresa de economia solidária. No entanto, depois do terremoto de 2010 e consequentemente com o fechamento de escolas, a maioria das leiteiras tem lutado para vender seus produtos. Porém, segundo os especialistas consultados por Phares Jerôme é na produção local que as autoridades haitianas devem investir se quiserem tirar o país da situação econômica desastrosa em que se encontra.

No capítulo quinto, cujo nome é Cultura como vitrine, escrito por Nélio Joseph, é exposta a vitalidade cultural haitiana e este é um espaço privilegiado que faz a força do Haiti e é um dos poucos setores que ainda atrai o olhar positivo da comunidade estrangeira. A cultura haitiana é resultante muitas das vezes de uma de suas religiões: o vodu, que é uma tradição cultural e religiosa que resulta de uma combinação de conhecimentos e práticas ancestrais deixadas pelos africanos. Segundo este capítulo, o vodu teve uma importância fundamental na vida da população e como tradição cultural integra todas as expressões artísticas autênticas haitianas: os cantos tradicionais, a música, a pintura, a dança e etc. No vodu haitiano, Deus é uma mulher: Yèhwe. O vodu 
jamais foi respeitado à altura de sua popularidade, sempre foi bombardeado pelos governantes que sucederam após a independência e pelo clero católico, apesar de constituir um dos três pilares da cultura haitiana: o lakou, o vodou e o kreóle (crioulo haitiano).

Nélio Joseph nos diz que a identidade haitiana seria também a capacidade de resistência histórica popular que sempre quis proteger os ganhos físicos e culturais em detrimento da destruição provocada por diversas circunstâncias. Graças ao seu histórico de resistência, os escravos construíram quilombos e toda uma estratégia de resistência contra o Estado, sendo preciso se esconder e se afastar de todos os laços com a sociedade oficial para assim, exercer sua religião. $\mathrm{O}$ autor diz que existem ainda alguns traços culturais fortes no Haiti que não são enquadrados na globalização cultural comandada pelo Ocidente e que esses traços se encontram notadamente na cultura popular.

$\mathrm{O}$ artesanato haitiano decora grandes boutiques internacionais de objetos decorativos. É um dos domínios em que a riqueza do Haiti tem muita vivacidade, presente em todos os lugares: no carnaval, nas festas campestres, nas galerias de objetos decorativos, nos mercados sobre as calçadas. E se apresenta também em uma diversidade animadora: ferro cortado, bordado, argila, madeira, pedra, papel machê, cerâmica, porcelana etc. É um setor de atividade cada vez mais prospero e criativo.

Neste capitulo o autor faz um panorama da riqueza cultural haitiana da qual o Estado, sempre atolado nas suas urgências sociais, revela-se frequentemente apenas como espectador e acrescenta que as iniciativas que deixaram vivo o setor cultural no Haiti são originárias de associações de artistas dos centros culturais privados, das embaixadas, dos institutos culturais estrangeiros e estas estruturas de acolhimento aos eventos culturais, já precárias antes, foram colocadas em prova após o terremoto.

E por fim, o último capítulo de nome Construindo a própria resistência, escrito por Adriana Santiago, Benedito Teixeira e Paola Vasconcelos, nos traz soluções alternativas elaboradas pelo povo haitiano, propiciando uma autonomia política, pois como os autores afirmam hoje o Haiti vive sob o jugo de aproximadamente 25 países, por meio de milhares de organizações não governamentais (ONGs) e forças de ocupação, que estão em terras haitianas, alguns com motivos declarados até "nobres". Mesmo assim, os autores concluem que por meio de pequenas ações, o que se percebe é que existe uma força latente que pode mudar o País e o mais incrível, que emerge num contexto de superexploração nos mais variados níveis - político, econômico, cultural, social e ambiental.

Neste capitulo é enfatizado que o futuro do Haiti na qualidade de país democraticamente participativo também se deve, em grande parte, à luta das mulheres. $\mathrm{Na}$ medida em que denuncia a realidade da exploração capitalista, a Solidariedade para as Mulheres Haitianas (Sofa) tenta prover as mulheres de meios que as tornem independentes economicamente, sobretudo na área da soberania alimentar. No Haiti,

Revista Eletrônica da ANPHLAC, ISSN 1679-1061, n. 16, p. 249-255, Jan./Jul. 2014.

http://revista.anphlac.org.br 
segundo o dirigente da Sofa, o poder visível não é realmente um poder que beneficia o povo. O verdadeiro poder no Haiti é o poder econômico, daqueles que têm o dinheiro nas mãos, os mesmos que se opõem às decisões políticas do País e que banem a qualquer custo a ideia de se criar um poder à esquerda. As classes dominantes não se abrem a novas ideias, à mudança, ao progresso, a plataformas que defendem entidades como a Sofa e a Papda.

Os autores concluem o livro direcionando uma reflexão sobre a reconstrução na retomada do controle da nação. Afirmam que a situação social caótica do Haiti também é reflexo da ajuda humanitária que transformou o país numa das principais fontes de recursos de milhares de ONGs que atuam há décadas no país, mas não produzem resultados que consigam, de fato, melhorar de forma sustentável a vida do povo. E o terremoto veio aprofundar essa situação de dificuldades, pois grande parte do apoio financeiro internacional anunciado não foi efetivada. Além disso, há problemas políticos internos entre o Executivo e o Legislativo que dificultam o andamento dos processos administrativos do país, ou seja, as pequenas iniciativas são muito morosas devido à instabilidade política. No entanto, mesmo diante desse quadro desanimador, existe uma essência lutadora no povo haitiano: existe um conjunto de movimentos de mulheres, campesinos, universitários, territoriais etc., que, com suas ações e o devido tratamento pelo Estado e pela importância ajuda humanitária internacional, podem fortalecer as iniciativas de democracia participativa. 